\title{
APONTAMENTOS SOBRE O DIREITO À SAÚDE E UM BREVE ESTUDO DE CASO: A Aplicação da Decisão do RE 657.718 do Supremo Tribunal Federal em uma Demanda por Saúde na Cidade de Tavares - RS
}

\author{
http://dx.doi.org/10.21527/2176-6622.2019.52.106-114
}

Recebido em: 22/10/2019

Modificações requeridas em: 28/10/2019

Aceito em: 4/11/2019

\section{Guilherme Camargo Massaú}

Professor da Faculdade e do Mestrado em Direito da UFPel. Pós-doutor na PUCRS. Doutor em Direito pela Unisinos. Mestre em Ciências Jurídico-Filosóficas pela Universidade de Coimbra. Especialista em Ciências Penais pela PUCRS. http://orcid.org/0000-0001-5955-4292. http://lattes.cnpq.br/8341523169751885. uassam@gmail.com

\section{Carolina Polvora Bica}

Servidora pública da Procuradoria Municipal de Tavares/RS - representante legal do município. Advogada. Mestranda em Direito na Universidade Federal de Pelotas. Especialista em Direito Público pela Escola da Magistratura Federal do Rio Grande do Sul e pós-graduada em Direito Tributário (Esmafe/RS-FEDST). http://lattes.cnpq.br/8781892482274970. carolinabica@outlook.com.br

\section{RESUMO}

O presente artigo tem como escopo tecer considerações acerca do direito à saúde tendo em vista um caso concreto em que poderia ser aplicada a recente decisão do Supremo Tribunal Federal (STF), que afastou o custeio estatal de tratamentos de saúde custosos sem comprovação de eficácia reconhecida pela Agência Nacional de Vigilância Sanitária (Anvisa). Será primeiramente realizado breve estudo acerca do direito à saúde com a finalidade de situá-lo nas categorias dogmáticas. Tais categorias serão também, ainda que de modo breve, analisadas ao se fazer um contraponto com a reserva do possível. Após a categorização e delimitação do direito à saúde no ordenamento jurídico brasileiro, passar-se-á ao estudo da decisão do RE n. 657.718 do STF, para, então, finalmente, serem feitas ponderações sobre seu possível reflexo no caso concreto. O método empregado é o hipotético-dedutivo, pois se analisará um caso de possível aplicação de decisão do STF. O meio de pesquisa empregado é o bibliográfico, sendo feito o uso de dados no que se refere à decisão do STF.

Palavras-chave: Direitos sociais. Direito à saúde. Recurso Extraordinário n. 657.718.

NOTES ABOUT THE RIGHT TO HEALTH AND A BRIEF CASE STUDY:

\section{THE APPLICATIN OF THE RE 657.718 DECISION OF THE SUPREME COURT IN A DEMAND FOR HEALTH IN THE TAVARES' TOWN}

\section{ABSTRACT}

This article has the objective of to write considerations about the right to health analysing a concrete case where it would be possible to aply a recente decision of the Supreme Court which stabilished that the state would not to pay expensive treatments of healthy without comproved eficacy recognised by Anvisa. First of all it will study the right to healthy in order to classificate it in a dogmatic category. That categories will be, in a brief way, analized when compared whith the possible reservation. After the categorization and the delimitation of the right to healthy in the brazilian law, it will study the decision RE n. 657.718 of the Supreme Court of Brazil, that in order to, finally do considerations about the consequences of the decision. The research used the bibliographic method and datas about the decision of Supreme Court, object in analisis.

Keywords: Social rights. Right to healthy. Decision of Supreme Court 657.758.

\section{SUMÁRIO}

1 Introdução. 2 Direito Fundamental Social à Saúde. 3 Os Direitos Fundamentais Sociais e a Reserva do Possível: Breves Digressões. 4 O Direito Social Essencial à Saúde e sua Prestação na Realidade Brasileira. 5 A Decisão do RE n. 657.718 do STF. 6 Da Aplicação da Decisão do RE n. 657.718 em um Caso Concreto. 7 Considerações Finais. 8 Referências. 


\section{INTRODUÇÃO}

O artigo tem como objetivo demonstrar a importância da decisão do Supremo Tribunal Federal (STF), de 23 de maio de 2019, no que diz respeito às demandas de fornecimento de remédios de alto custo que não tenham comprovada a sua eficácia. Para se chegar a esse objetivo, invocar-se-á uma demanda judicial envolvendo o município de Tavares no Rio Grande do Sul.

O tema "saúde" é da maior relevância, posto que trata de direito social fundamental. A decisão que será analisada, todavia, apresenta elementos polêmicos no que se refere à prestação de tratamentos custosos sem eficácia reconhecidamente comprovada e que leva, muitas vezes, a uma decisão que potencializa o risco de morte à pessoa humana que pleiteou o direito e não obteve a tutela jurisdicional.

Dessa feita, perante a finitude de recursos que dispõem o Estado e em razão do princípio da reserva do possível, é necessário reconhecer que se pode tratar de uma escolha de Sofia, na medida em que o Estado estaria limitado, ante os seus recursos financeiros, diante dos avanços da medicina e, com isso, incapaz de ofertar aos pacientes tratamentos avançados, porém ainda sem determinados parâmetros de comprovação. Isso acarreta uma série de problemas, sendo um deles a limitação orçamentária do Estado para atender todas as demandas de saúde.

Por consequência, o caso oriundo do município de Tavares mostra o impacto orçamentário diante de uma demanda com uma prestação de saúde cujo resultado é incerto em termos do reconhecimento dos órgãos técnicos do Estado. Neste ponto encontra-se o aspecto crucial da legitimidade do direito pleiteado por parte da demandante. Se a demandante conseguir o tratamento, por conseguinte faltará recursos para outras demandas correntes de prestação de saúde. Se, porém, não conseguir, terá acentuado o risco de morte. Entre essas duas possibilidades situa-se o fato de o tratamento não ter sua eficácia plenamente comprovada pelos órgãos competentes do Estado brasileiro, no caso a Agência Nacional de Vigilância Sanitária (Anvisa).

\section{DIREITO FUNDAMENTAL SOCIAL À SAÚDE}

O direito fundamental social à saúde situa-se na segunda dimensão de direitos humanos e fundamentais. Assim, trata-se de um direito social previsto no Artigo 60 da CF e densificado pelo artigo 196 ao artigo 200 da CF. Além da classificação histórica, ele é considerado direito prestacional - em sua característica marcante -, sendo o Estado constitucionalmente responsável por estruturar, manter e desenvolver um sistema de saúde capaz de, universal, gratuito, de modo integral e igualitariamente, promover, proteger e recuperar a saúde dos indivíduos (artigo 196, in fine, da CF).

Por conseguinte, identificado o direito à saúde como direito constitucionalmente previsto e, ainda, direito fundamental, surge a questão da sua exigibilidade. Em termos de localização no ordenamento jurídico, o fato de ser um direito derivado de norma de direito constitucional, o situa com força normativa (HESSE, 1993, p. 28) suficiente para ter, ao menos, um mínimo de exigibilidade. Tanto que o artigo 5o, §1으, da CF estabelece a aplicação imediata das normas que definem direitos e garantias sociais, e isso inclui o artigo 60 da CF. Ao observar, contudo, as características do artigo 60 e do artigo 196 ao artigo 200 da CF, pode-se inferir que se trata de direito de baixa densidade normativa (SARLET; MARINONI; MITIDIERO, 2014 , p. 184), ou seja, o texto constitucional traz normas que necessitam de densificação infraconstitucional para que o Estado possa concretizar o acesso à saúde em toda a sua complexidade. A ausência de normas complementares, no entanto, não afasta o surgimento do direito subjetivo.

Destaca-se, por conseguinte, que as pretensões são ilimitadas, mas os recursos financeiros do Estado são limitados. Desta forma, mesmo que a CF estabeleça o acesso universal às prestações relacionadas à saúde, os recursos financeiros não são suficientes para suportar a demanda. Por isso, o Estado-administração delimita, estrategicamente, os recursos financeiros e os meios a serem utilizados na concretização da saúde. Isto implica definir as pretensões consideradas legítimas e as não legítimas. Com isto, surge a reserva do possível, argumento utilizado pelo Estado quando se encontra diante de uma pretensão à prestação da saúde que supera seu orçamento financeiro. 


\section{Direito自

\section{OS DIREITOS FUNDAMENTAIS SOCIAIS E A RESERVA DO POSSÍVEL: Breves Digressões}

Aqui será tratado brevemente sobre os direitos econômicos, sociais e culturais, para contrapô-los ao princípio da reserva do possível, posto que demandam de investimentos estatais diretos para a sua consecução, uma vez que, conforme Sarlet (2018, p. 47): "Não se cuida mais, portanto, de liberdade, do e perante o Estado, e sim de liberdade por intermédio do Estado". Por conseguinte, defende-se que, somente por meio da instituição dos direitos fundamentais sociais é que se podem realizar os chamados direitos de liberdade, sendo os primeiros a condição ao exercício efetivo dos direitos de liberdades. Isso pelo fato de que os direitos de primeira dimensão são assegurados ao se garantir a cada indivíduo o mínimo de bem-estar econômico e uma vida digna (BOBBIO, 2004, p. 206).

A CF é o instrumento de garantia do mínimo de bem-estar econômico. Para tanto, o Estado precisa de mais recursos, precisa deter meios econômicos e intervir na economia para proteger os indivíduos nos aspectos sociais. Ocorre que o Estado esbarra em um limite denominado "reserva do possível". Tal expressão

foi difundida a partir de célebre decisão do Tribunal Constitucional alemão, proferida em 1972, em caso conhecido como Numerus Clausus (ALEMANHA, Tribunal Constitucional, 1972), que tratou da validade da limitação do número de vagas em universidades públicas, tendo em vista a pretensão de ingresso de um número maior de candidatos. Não há, na Constituição alemã, a garantia do direito à educação, mas o Tribunal Constitucional entendeu que a liberdade profissional demandava, em alguma medida, o direito de acesso ao ensino superior. Todavia, frisou que tal direito "se encontra sob a reserva do possível, no sentido de estabelecer o que o indivíduo pode razoavelmente exigir da sociedade". Segundo a Corte germânica, tal decisão cabe primariamente ao legislador, que deve "atender, na administração do seu orçamento, também a outros interesses da coletividade" (SARMENTO, 2016, p. 1.671).

Ora, de fato os direitos sociais apresentam uma divisa fática à sua efetivação, que, como visto, está na real existência de recursos por atribuição dos cofres públicos para efetivar com suas obrigações. Além dessa divisa fática, encontra-se também limite quanto à possibilidade jurídica do Estado de fruir desses recursos, quando efetivos. Essas duas divisas consistem na formação da chamada "reserva do possível" (SARLET; FIGUEREIDO, 2008, p. 189). Consoante Silva (2010, p. 593), os direitos sociais possuem custos, assim como os direitos civis, mas aqueles requerem maior investimento por parte do Estado. Para Cordeiro (2012), não seria o Judiciário o Poder que deveria atender às questões concernentes aos direitos sociais, uma vez que falta aos juízes uma "visão global das necessidades desatendidas":

Prova disso é o impacto da judicialização do direito à saúde no orçamento público. No ano de 2010, o Ministério da Saúde gastou R\$135,58 milhões com a compra de medicamentos de alto custo cujo fornecimento fora determinado judicialmente. (...) O Estado do Rio Grande do Sul já teve 50\% de todo orçamento destinado à saúde comprometido com a compra de medicamentos por ordem judicial. Segundo o balanço do Conselho Nacional de Justiça, mais de 240 mil processos judiciais na área da saúde tramitam atualmente (p. 164-165).

Nesse sentido, a reserva do possível não impossibilita que o Poder Judiciário possa "zelar pela efetivação dos direitos sociais" (SARLET; FIGUEREIDO, 2008, p. 190), mas deve concebê-lo com moderação e sensatez, consciente do problema de carência de recursos. Paradoxalmente, no entanto, a reserva do possível é utilizada como justificativa para a não intervenção do Judiciário em se tratando de direitos sociais. Logo, compete ao Poder Público o encargo de provar a ausência de recursos e de provar que executa sua obrigação de administrá-los eficientemente, o que foi, inclusive, expressamente estabelecido no STA $223 \mathrm{Agr}^{1}$ :

Cumpre advertir, desse modo, que a cláusula da "reserva do possível" - ressalvada a ocorrência de justo motivo 80 STF: RE 410.715/SP, Rel. Min. Celso de Mello, j. 22/11/2005, p. 13. 55 objetivamente aferível - não pode ser invocada, pelo Poder Público, com a finalidade de exonerar-se, dolosamente, do cumprimento de suas obrigações constitucionais, notadamente quando, dessa conduta governamental negativa, puder resultar nulificação ou, até mesmo, aniquilação de direitos constitucionais impregnados de um sentido de essencial fundamentalidade.

STA 223, Relator(a): Min. PRESIDENTE, Decisão Proferida pelo(a) Ministro(a) ELLEN GRACIE, julgado em 12/3/2008, publicado em DJe-049 DIVULG 17/3/2008 PUBLIC 18/3/2008. 
A Suspensão de Tutela Antecipada de no 223 (STA 223 Agr) trata do caso de uma vítima de assalto de Pernambuco que pleiteou o custeio de cirurgia a ser realizada no exterior. Segundo o ministro Celso de Mello, a garantia do mínimo existencial deveria se sobrepor ao argumento da reserva do possível dada ainda a responsabilidade objetiva do Estado em custear a cirurgia de pessoa que fora vítima de assalto em razão de falha no dever de segurança.

Fora decidido, todavia, que, no caso, deveria ser deferido o pedido de suspensão da tutela cautelar pelo fato de que ocorreria grave lesão ao erário e infração administrativa se a decisão cautelar fosse mantida, uma vez que essa ordenava a realização de cirurgia de alto custo não prevista no Sistema Único de Saúde e sem garantia de que os recursos enviados para o exterior seriam, de fato, utilizados para o fim da feitura do procedimento médico. Na decisão do STA $223 \mathrm{Agr} / \mathrm{PE}$, além de se entender que restou violado o artigo 196 da Carta Magna em virtude de que o "tratamento médico sequer existente no país, de caráter experimental e sem qualquer prova de eficácia ou aplicabilidade ao caso do paciente", ainda foram estabelecidos importantes critérios:

a) competência da Presidência do Supremo Tribunal Federal para a análise do presente pedido de suspensão de tutela antecipada, tendo em vista que a ação principal tem por fundamento matéria constitucional: arts. 37, § 6. ', 100 e 196 da Constituição da República;

b) a existência do perigo na demora, ante o fato de que "a decisão está em vias de ser executada, já tendo sido determinada a transferência dos recursos que foram depositados em conta judicial, para uma conta bancária no exterior, pertencente ao médico norte-americano que a família alega que virá ao Brasil para operar o recorrido" (fl. 05);

c) a ocorrência de grave lesão à ordem pública, considerada em termos de ordem jurídico-administrativa, dada a iminência de transferência de recursos públicos ao exterior, "para pessoa não domiciliada no país, sem prévia autorização do Banco Central do Brasil" (fl. 07).

d) a ocorrência de grave lesão à economia pública, consubstanciada na determinação do pagamento em tela sem o prévio trânsito em julgado da sentença condenatória e sem a obrigatória expedição de precatório, em afronta direta ao art. 100, da Constituição da República (fl. 10/11).

e) violação ao disposto no $\S 6^{\circ}$ do art. 37 da Constituição Federal, diante da inexistência de nexo de causalidade entre o Estado requerente e o dano provocado na vítima em "um assalto à mão armada, praticado por terceiro" (fls. 11/13);

f) a ocorrência de grave lesão à economia pública, ante a possibilidade de ocorrência do denominado "efeito multiplicador", diante do risco de proliferação de demandas objetivando que o Estado arque com os custos dos procedimentos terapêuticos desejados "em qualquer lugar do mundo" (fls. 15/16);

Observa-se que a decisão do STA 223 Agr/PE já sinalizava, nos idos de 2008, um possível posicionamento do Supremo Tribunal Federal, o qual somente fora obtido com a decisão proferida no RE 657.718, a qual será minudenciada no tópico a seguir.

Sarlet e Figueiredo (2008, p. 190) equiparam-se com posicionamentos que resguardam que a reserva do possível deve ser relativizada no momento em que está na perspectiva do mínimo existencial, posto que este cria direito subjetivo a prestações, assim como deve ser auferido nos intentos orçamentários. No momento em que o mínimo existencial estiver em causa, dispõem-se um direito subjetivo a contribuições que são integralmente exigíveis pela via jurisdicional, uma vez que deve preponderar a vida e a dignidade da pessoa acima de impasses quanto à reserva do possível.

Neste contexto, dada a íntima conexão desta problemática com a discussão em torno da assim designada "reserva do possível" na condição de limite fático e jurídico à efetivação judicial (e até mesmo política) de direitos fundamentais - e não apenas dos direitos sociais, consoante já frisado - vale destacar que também resta abrangida na obrigação de todos os órgãos estatais e agentes políticos a tarefa de maximizar os recursos e minimizar o impacto da reserva do possível (SARLET; FIGUEREIDO, 2008, p. 191).

Já Barcellos (2011, p. 321-322) afirma que a atuação do Judiciário deve se limitar a atender ao mínimo, mas deve se ater somente a ele e não extrapolar: 
O Judiciário poderá e deverá determinar o fornecimento das prestações de saúde que compõe o mínimo, mas não devera fazê-lo em relação a outras, que estejam fora desse conjunto. Salvo é claro, quando as opções políticas dos poderes constituídos - afora e além do mínimo - hajam sido juridicizadas e tomem a forma de uma lei. Também aqui caberá ao Judiciário dar execução - eficácia ou simétrica - à lei.

É preciso levar em consideração a realidade econômica do Estado. Logo, é necessário que a reserva do possível fática não seja restrita apenas à pretensão individual demandada em juízo. Trata-se de uma exigência do princípio da igualdade que o Estado conceda a um indivíduo aquilo que possua condições de conceder aos outros que estiverem na mesma situação. Nesse sentido, a reserva do possível fática deve ser entendida como capacidade financeira do Estado no sentido de sustentar a universalização da pretensão material postulada no Judiciário (SARMENTO, 2016, p. 1.672).

Observa-se, assim, que os temas correlatos ao objeto central do presente trabalho, qual seja, a decisão Recurso Extraordinário (RE) n. 657.718, estudado no item 5 infra, são, por si mesmos, passíveis de discussão, tais como os que foram aqui abordados, ainda que sem a devida profundidade pela limitação espaço-temporal, como o próprio princípio da reserva do possível. No tópico seguinte se explanará como encontravam-se as decisões relativas às demandas por saúde antes do proferimento do decisum paradigmático do Supremo.

\section{O DIREITO SOCIAL ESSENCIAL À SAÚDE E SUA PRESTAÇÃO NA REALIDADE BRASILEIRA}

A Constituição de 1988 (artigo 6ㅇ) estabeleceu o direito à saúde como direito fundamental (SILVA, 2010, p. 308). A importância desse direito na CF pode ser notada pela sua densificação constitucional contida nos artigos 196 e 200, quando, juntamente com a seguridade social, deve ser assegurado e concretizado. Ressalta-se, ainda, que o direito à saúde é universal, gratuito, descentralizado, integral e com equidade, sendo que todos, sem nenhuma distinção, são possíveis usuários dos serviços de saúde prestados pelo Estado por meio de políticas públicas que promovam a saúde, evitando e combatendo as doenças da população.

Em paralelo com o Estado, o artigo 197 prevê a possibilidade de prestação de serviços de saúde por particulares - tanto pessoas físicas quanto jurídicas - desde que sejam atendidas as exigências normativas do Poder Público que regulamentam não somente o fornecimento de serviço de saúde, mas a sua fiscalização e controle. Destarte, como se trata, preponderantemente, de serviço, o direito à saúde "exige prestações de Estado e que impõe aos entes públicos a realização de determinadas tarefas (...), de cujo cumprimento depende a própria realização do direito" (SILVA, 2010, p. 309).

Assim, em caso de não ser atendido este direito pelo Poder Público, é possível que seja acionado o Poder Judiciário por meio de ação de inconstitucionalidade por omissão, a Adin por omissão, prevista no artigo 102, I e 103, §2ㅇ da Constituição. Já o sujeito de direito, que é qualquer pessoa, dada a universalidade deste direito, tem direito subjetivo de, respeitada a legitimidade para a propositura da ação, impetrar mandado de injunção nos termos do artigo 5o, LXXXI também da Carta Magna (SILVA, 2010, p. 309-310).

Discute-se sobre essa "intromissão" do Poder Judiciário no que se refere à imposição de realização de políticas públicas para o Poder Público, em geral para o Executivo. Ocorre que o mínimo existencial deve ser tutelado conforme expresso na Constituição, logo há obrigação constitucionalmente prevista de prestações de saúde que, se não atendidas livremente pelos poderes públicos, implicam possibilidade de se pleitear perante o Poder Judiciário para que não ocorra um atentado à dignidade da pessoa humana (BARCELLOS, 2011, p. 321).

Tratar, entretanto, de modo abstrato o dever de prestação estatal, sem o devido estudo econômico para que na realidade sejam apuradas quais as possibilidades do Estado, torna a pretensão normativa totalmente inexequível. Assim, como parâmetro geral da realidade doutrinária brasileira, traz-se o estudo de Acca, que afirma que tratar de direitos sociais somente abstratamente, trazendo à tona a dignidade da pessoa humana, o mínimo existencial e um punhado de "frases de efeito", sem o devido aprofundamento teórico e, principalmente, sem se tratar da realidade com análise empírica de dados, faz com que não seja possível entender, de fato, a realidade (ACCA, 2009, p. 146). 
A decisão do RE n. 657.718, que teria vindo em sentido oposto para adequar minimamente a um parâmetro, objetiva o fornecimento de tratamentos custosos, consoante será estudado no tópico a seguir, mas, antes, retomam-se outros casos correlatos já decididos pelo STF, que, segundo Leivas (2006), quando da análise do agravo regimental no RE n. 271.286-8 já havia se posicionado no sentido de que o direito fundamental à saúde é um direito público subjetivo.

O caso concreto deu-se em uma demanda por saúde em que foram acionados o município de Porto Alegre e, concomitantemente - dado a solidariedade dos entes públicos na prestação de saúde -, o Estado do Rio Grande do Sul. Fora interposto recurso extraordinário pelo município de Porto Alegre, uma vez que o Tribunal de Justiça do Rio Grande do Sul havia condenado a municipalidade ao fornecimento de medicamentos, de modo gratuito, para tratar a Aids ou retardar a incorporação do HIV para os seus portadores de baixa renda. Em sua defesa, o município afirmou que a decisão violava o artigo 167, I, da CF, que trata de políticas públicas sem legislação específica e não incluídas na lei orçamentária do ente público, além da separação dos poderes (LEIVAS, 2006, p. 118).

Existia, então, uma lei que tratava do fornecimento dessa classe de medicamentos, somente lhe faltava regulamentação. Daí que o STF entendeu que há direito subjetivo à saúde para todos e isso está previsto na Constituição. Destarte, não impede o fornecimento de tratamento de saúde a inexistência de lei específica, uma vez que o direito subjetivo à saúde tem seu fundamento na Constituição (LEIVAS, 2006, p. 118). Ainda, Leivas (2006, p. 118) defende que o direito fundamental à saúde deve prevalecer quando colidir com a competência orçamentária do legislador. Esse posicionamento é criticado por Acca (2009).

O STF sinalizou uma mudança com a decisão do RE n. 657.718, estabelecendo parâmetros objetivos para serem observados nas futuras decisões judiciais. Como exemplo, a necessidade da presença do medicamento na lista da Anvisa, conforme será especificado na sequência.

\section{A DECISÃO DO RE N. 657.718 DO STF}

A decisão, objeto do presente estudo, fora proferida pelo Plenário do STF no dia 22 de maio do ano de 2019, que deu repercussão geral à questão da existência ou não da obrigação de os entes públicos fornecerem medicamentos sem registro na Anvisa em virtude do direito à saúde assegurado pela Constituição. ${ }^{2}$ Desta forma, restou decidido, por maioria de votos, o tema de repercussão geral de número 500, o qual dispõe que, em que pese a exigência normativo-constitucional de acesso à saúde, essa não implica dever de prestação de medicamentos experimentais, independente de sua fase de pesquisa, quanto à eficácia medicamentosa contra a doença.

Por consequência, o STF adotou o parâmetro da necessidade de registro do medicamento na Anvisa; logo, como regra, se a medicação não está registrada, a administração não está obrigada a fornecê-la nem cabe sua obtenção por meio de decisão judicial. Em geral, os medicamentos experimentais são de alto custo, e, dada a não comprovação de sua eficácia, implicam custos infundados ao Estado (BRASIL, 2019a).

Ocorre que foram estabelecidos parâmetros que possibilitam que se obtenha medicamentos ainda em fase experimental. Para tanto, é necessário, primeiramente, que exista prévia solicitação de registro do medicamento - exceto em caso de doença rara ou ultrarrara -; em segundo lugar, o medicamento deve ter registro em agências de regulação no exterior; e, por fim, deve inexistir medicamento substituto no país. Ainda, restou estabelecida a legitimação passiva da União nas ações que tratam da matéria (BRASIL, 2019a).

Restou decidido que o Estado, tanto os municípios quanto os Estados da Federação, o Distrito Federal e a União, não podem ser obrigados a fornecer medicamento que não possua a sua eficácia comprovada, logo, que esteja ainda em fase experimental ou não possua registro na Anvisa, salvo em casos excepcionais em que devem ser observados requisitos objetivos elencados na decisão (BRASIL, 2019a). Isso pelo fato de o decisum

\footnotetext{
SAÚDE - MEDICAMENTO - FALTA DE REGISTRO NA AGÊNCIA NACIONAL DE VIGILÂNCIA SANITÁRIA - AUSÊNCIA DO DIREITO ASSENTADA NA ORIGEM - RECURSO EXTRAORDINÁRIO - REPERCUSSÃO GERAL - CONFIGURAÇÃO. Possui repercussão geral a controvérsia acerca da obrigatoriedade, ou não, de o Estado, ante o direito à saúde constitucionalmente garantido, fornecer medicamento não registrado na Agência Nacional de Vigilância Sanitária - ANVISA. (RE 657.718 RG, Relator(a): Min. MARCO AURÉLIO, julgado em 17/11/2011, ACÓRDÃO ELETRÔNICO DJe-051 DIVULG 09-3-2012 PUBLIC 12-3-2012 REPUBLICAÇÃO: DJe-092 DIVULG 10-5-2012 PUBLIC 11-5-2012).
} 
ter repercussão geral reconhecida, ou seja, efeito vinculante para demais decisões de casos similares. Cabe ressaltar que a relatoria do caso fora do ministro Marco Aurélio, e, a seguir, será feito brevíssimo estudo dos votos.

O julgamento iniciou em 2016 e foi retomado, em sessão extraordinária, em maio de 2019, com o voto-vista do ministro Alexandre de Moraes. Esse acompanhou a divergência aberta pelo ministro Luís Roberto Barroso no sentido do provimento parcial ao recurso. Em seu voto-vista, Moraes afirmou que "Não se trata de negar direito fundamental à saúde. Trata-se de analisar que a arrecadação estatal, o orçamento e a destinação à saúde pública são finitos", e concluiu pela constitucionalidade do artigo 19-T da Lei 8.080/1990, ${ }^{3}$ que veda, em todas as esferas de gestão do SUS, o pagamento, o ressarcimento ou o reembolso de medicamento experimental ou de uso não autorizado pela Anvisa (BRASIL, 2019a).

Para o ministro Alexandre de Moraes, ainda, caso não seja assim não se terá universalidade, mas seletividade, quando aqueles que obtêm uma decisão judicial acabam tendo preferência em relação a toda uma política pública planejada. Consoante noticiado, os ministros que votaram contrariamente à posição vencedora foram Rosa Weber, Luiz Fux, Cármen Lúcia, Ricardo Lewandowski e Gilmar Mendes. Segundo esses ministros, o Estado tem o dever de fornecer até os medicamentos sem registro, posto que se tratam de casos excepcionais. Já Edson Fachin também votou no sentido de que caberia ao Poder Público fornecer os medicamentos, e mais, esse deveria fixar os parâmetros para a concessão (BRASIL, 2019a).

O ministro Dias Toffoli, que votou no sentido de acompanhar o relator ministro Marco Aurélio, entendeu que nenhum medicamento pode ser comercializado sem registro na Anvisa e ressaltou que o contrário configura prática criminosa prevista no artigo 273, parágrafo 10-B, do Código Penal. Desse modo, negaram provimento ao recurso. Ainda, segundo o presidente do STF, a regulamentação dos medicamentos pela Anvisa permite o controle dos preços pelo Poder Público. Também por maioria de votos, fixou-se a seguinte tese de não ser responsabilidade do Estado fornecer medicamentos experimentais; para que sejam fornecidos, os medicamentos devem ter registro na Anvisa; como exceção, existindo o pedido de registro na Anvisa, e diante da demora para efetivar o registro, exceto no caso de doenças "raras e ultrarraras", seria possível a obtenção de medicamentos; assim como nos casos de haver registro do medicamento em agências renomadas no exterior, ou ainda não existir outro recurso medicamentoso registrado (BRASIL, 2019).

Restou ainda estabelecido que, a competência para ajuizamento de ações que pleiteiam medicamentos sem registro da Anvisa é da União. A decisão fora julgada com aplicação de repercussão geral. Desta feita, identificam-se parâmetros objetivos para se obter tutela jurisdicional do que se pleiteia em relação ao direito à saúde.

\section{DA APLICAÇÃO DA DECISÃO DO RE N. 657.718 EM UM CASO CONCRETO}

O caso concreto escolhido para breve análise é uma demanda de saúde originária da cidade de Tavares/RS, na qual a autora é uma idosa de 93 anos, portadora de gonartrose primária bilateral (CID 10 M 17.0), quando fora proferida em Recurso Inominado decisão da Terceira Turma Recursal da Fazenda Pública do Tribunal de Justiça do Rio Grande do Sul (TJRS), que tratou do pedido de fornecimento dos medicamentos sulfato de glicosamina, peptídeo de colágeno, Cloridrato de tramadol e celecobixe. No caso dos autos restou comprovada a necessidade do requerente e entendeu-se ainda que o "direito à vida se sobrepõe a regulamentações administrativas do ente público". ${ }^{4}$ Como é de praxe, dado o que estabelece a Constituição, ficou estabelecida a responsabilidade solidária entre os entes federados para o atendimento integral à saúde (RIO..., 2019).

\footnotetext{
“Art. 19-T. São vedados, em todas as esferas de gestão do SUS: (Incluído pela Lei no 12.401, de 2011) I - o pagamento, o ressarcimento ou o reembolso de medicamento, produto e procedimento clínico ou cirúrgico experimental, ou de uso não autorizado pela Agência Nacional de Vigilância Sanitária - Anvisa; (Incluído pela Lei no 12.401, de 2011).

II - a dispensação, o pagamento, o ressarcimento ou o reembolso de medicamento e produto, nacional ou importado, sem registro na Anvisa."

4 Recurso Cível, n. 71007823545, Terceira Turma Recursal da Fazenda Pública, Turmas Recursais, Relator: Lílian Cristiane Siman, Julgado em: 23-5-2019.
} 
Salienta-se que o medicamento sulfato glicosamina apresenta ausência de comprovação de eficácia do fármaco presente em nota técnica do Ministério da Saúde. Assim, não há como exigir o fornecimento pelo Estado. Logo, nesse ponto em específico, a sentença de procedência fora reformada e foi provido parcialmente o recurso interposto pela municipalidade (RIO..., 2019).

A recente decisão do STF, coincidentemente proferida no mesmo dia do julgamento do Recurso Inominado, impossibilita a interposição formal de recurso contra a decisão, mas torna materialmente inviável a mudança, dada a repercussão geral do julgamento do RE n. 657.718. Sabe-se que a decisão do STF é polêmica, até pelo fato de tratar de direito social, que é pedra angular para o Estado Democrático de Direito, positivado pela primeira vez na Constituição Cidadã de 1988.

Desta feita, de acordo com Acca (2009), não basta trazer à baila o mínimo existencial e a dignidade da pessoa humana como fundamento para pleitear direitos sociais. É óbvia a afirmação de que o Estado deve garantir o mínimo existencial e a dignidade da pessoa humana por meio de direitos sociais. Os empregos desses argumentos necessitam de fundamentos, pois não basta o doente pleitear o direito à saúde sob os fundamentos do princípio da dignidade da pessoa humana, do mínimo existencial e da previsão genérica de seu direito à saúde. Deve-se considerar a questão de como o Estado - a Administração Pública - deve gerir o montante de pedidos iguais.

Isso significa pensar e executar as políticas públicas para que não se tornem um balcão em que aquele que protocolar seu pedido primeiro o tem atendido, em desfavor da coletividade. Para Acca (2009, p. 149), a questão da distribuição dos direitos sociais deve ser mais bem discutida, não somente se estruturando sobre conceitos abstratos sem efetividade na prática. Assim, da aplicação da decisão do RE n. 657.718 à decisão do caso concreto, qual seja, o Recurso Cível n. 71007823545, podem ser feitas algumas considerações.

Quando se está tratando de demanda sobre saúde, deve-se ter em vista o macrossistema como um todo. Assim,

Uma observação importante é a de que a hierarquização da rede de serviços não implica uma hierarquia entre União, Estados-membros e Distrito Federal e Municípios, os quais possuem autonomia no plano federativo. Por outro lado, o princípio da regionalização e hierarquização se articula com o da descentralização, o qual indica que a prestação de serviços se dê primordialmente pelos municípios. Todavia, essa descentralização deve ser responsável e com gradativa capacitação da esfera local (BARBOSA, 2014, p. 37).

Juntamente com isso, e por se tratar de Direito Público, o Estado não deve ser condenado a financiar um tratamento que pode ser custoso e ineficaz, assumindo o risco de faltarem recursos para tutelar a saúde dos demais cidadãos. É preciso levar em conta a escassez dos recursos financeiros perante a demanda de saúde. Nesse caso em análise (RE n. 657.718), os valores podem chegar, ao ano, em R\$112.109,76. O valor da causa é de $\mathrm{R} \$ 9.342,48$. Esse valor é o correspondente ao tratamento mensal da autora da ação.

Tal valor seria destinado a uma única pessoa. Destaca-se que a previsão do orçamento do município de Tavares, em 2017, foi de $R \$ 15.300 .000,00$, e a previsão de recursos para a saúde foi de $R \$ 4.112 .138,86$; em 2018, o orçamento total foi de $R \$ 16.232 .000,00$, e para a saúde foi de $R \$ 4.594 .240,00$; já em 2019, a previsão orçamentária foi de $R \$ 17.221 .887,66$, sendo reservado para a saúde $R \$ 5.114 .514,71,{ }^{5}$ destacando-se que é mais dos $15 \%$ do orçamento municipal previstos em lei.

Nesse caso, o Estado optaria por apostar seus recursos financeiros em um tratamento medicamentoso incerto, que não possui registro na Anvisa, em detrimento de outros tratamentos reconhecidos. Não há diferenças de valores em relação a vidas que dependem do acesso à saúde. Destarte, o estabelecimento de parâmetros objetivos deu-se unicamente para vinculação dos Tribunais, do mesmo modo que se entende que a aplicação da decisão do RE n. 657.718 e do tema 500, com repercussão geral, pode, ainda e inclusive, trazer maior celeridade aos julgados.

Dados fornecidos pelo município de Tavares/RS. 


\section{Direito自

\section{CONSIDERAÇÕES FINAIS}

O texto teve como finalidade apresentar, a partir de um caso concreto, o acesso à prestação de saúde. Situou-se o direito à saúde no ordenamento jurídico pátrio em relação à sua aplicabilidade. Como se trata de um direito social, o mesmo caracteriza-se, especificamente, pela necessidade de o Estado efetuar a prestação. Para problematizar a temática, buscou-se trazer a decisão do STF do RE n. 657.718, a qual se entende que estabeleceu parâmetros a fim de otimizar a prestação à saúde e não a cercear, quando se pode isso entender em um primeiro momento.

Somou-se o caso concreto oriundo do município de Tavares/RS correspondente ao Recurso Cível n. 71007823545. Daí foram apresentadas breves explanações sobre a reserva do possível e o mínimo existencial para, então, ser realizada o contraponto na realidade brasileira entre o direito à saúde e a reserva do possível. Por isso, trata-se de tema importante e que merecerá futuras reflexões. Destaca-se que foram estabelecidas diretrizes para obtenção de medicamentos que já tenham sido aprovados pela Anvisa, mas ainda não regularizados pela mora da própria autarquia. Ainda, entende-se que a aplicação em repercussão geral do tema 500 traz celeridade ao sistema.

Por fim, buscou-se mostrar o impacto que a demanda referente ao município de Tavares impactaria no seu orçamento. Levou-se em conta três exercícios financeiros, posto que são os que correspondem aos anos da referida ação de acesso à prestação de saúde. O possível valor a ser gasto anualmente para custear somente o tratamento referente a essa ação, fica por volta de $5 \%$ do orçamento anual previsto para a área da saúde. Por conseguinte, é imperial refletir sobre a possibilidade de a população vir a arcar financeiramente com tratamentos experimentais, embora a decisão possa colidir com o direito à vida. A decisão, no entanto, tende a resguardar à dimensão coletiva financeira, pois é incabível que todos os contribuintes financiem tratamentos ainda não comprovados.

\section{REFERÊNCIAS}

ACCA, Thiago dos Santos. Uma análise da doutrina brasileira dos direitos sociais: saúde, educação e moradia entre os anos de 1964 e 2006. 2009. Dissertação (Mestrado em Filosofia e Teoria Geral do Direito) - Faculdade de Direito, Universidade de São Paulo, São Paulo, 2009.

BARBOSA, Jeferson Ferreira. Direito à saúde e solidariedade na Constituição brasileira. Porto Alegre: Livraria do Advogado, 2014. BARCELLOS, Ana Paula. A eficácia jurídica dos princípios constitucionais: o princípio da dignidade da pessoa humana. 3 . ed. Rio de Janeiro: Renovar, 2011.

BOBBIO, Norberto. A era dos direitos. Rio de Janeiro: Elsevier, 2004.

BRASIL. STF. Recurso especial: RE 657.718. Brasília. Disponível em: http://portal.stf.jus.br/processos/detalhe.asp?incidente $=4143144$. Acesso em: 10 jul. 2019a.

BRASIL. STF. Suspensão de tutela antecipada: STA 223. Brasília. Disponível em: http://stf.jus.br/portal/jurisprudencia/listarJurisprudencia.asp?s1=\%28STA\%24\%2ESCLA\%2E+E+223\%2ENUME\%2E\%29+E+S\%2EPRES\%2E\&base=basePresidencia\&url=http://tinyurl.com/aj28lcv. Acesso em: 29 out. 2019b.

CORDEIRO, Karine da Silva. Direitos fundamentais sociais: dignidade da pessoa humana e mínimo existencial, o papel do Poder Judiciário. Porto Alegre: Livraria do Advogado, 2012.

GRAU, Eros Roberto. Comentários ao artigo 170. In: CANOTILHO, J. J. Gomes; MENDES, Gilmar F.; SARLET, Ingo W.; STRECK, Lenio L. (coord.). Comentários à Constituição do Brasil. São Paulo: Saraiva; Almedina, 2013. p. 1.785.

HESSE, Konrad. Grundzüge des Verfassungsrechts der Bundesrepublik Deutschland. 19 Aufl. Heidelberg: C.F. Müller, 1993.

LEIVAS, Paulo Gilberto Cogo. Teoria dos Direitos Fundamentais Sociais. Porto Alegre: Livraria do Advogado, 2006.

PIOVESAN, Flávia. Temas de direitos humanos. São Paulo: Max Limonad, 1998.

RIO GRANDE DO SUL. TJRS. Recurso Cível n. 71007823545. Porto Alegre. Disponível em: http://www.tjrs.jus.br/site/busca-solr/ index.html?aba=jurisprudencia. Acesso em: 10 jul. 2019.

SARLET, Ingo Wolfgang. A eficácia dos direitos fundamentais. 13. ed. Porto Alegre: Livraria do Advogado Editora, 2018.

SARLET, Ingo Wolfgang; FIGUEIREDO, Mariana Filchtiner. Reserva do possível, mínimo existencial e direito à saúde: algumas aproximações. In: SARLET Ingo Wolfgang; TIMM, Luciano Benetti (org.). Direitos fundamentais, orçamento e "reserva do possível". Porto Alegre: Livraria do Advogado, 2008.

SARLET, Ingo Wolgang; MARINONI, Luiz Guilherme; MITIDIERO, Daniel. Curso de direito constitucional. 3. ed. São Paulo: Revista dos Tribunais, 2014.

SARMENTO, Daniel. O mínimo existencial. In: Revista de Direito da Cidade, Rio de Janeiro, vol. 8, n. 4, p. 1.644-1.689, 2016.

SILVA, José Afonso da. Curso de Direito Constitucional Positivo. 33. ed. São Paulo: Malheiros Editores, 2010.

SILVA, Virgílio Afonso da. O Judiciário e as políticas públicas: entre transformação social e obstáculo à realização dos direitos sociais. In: SOUZA NETO, Cláudio Pereira de; SARMENTO, Daniel (coord.). Direitos sociais: fundamentos, judicialização e direitos sociais em espécie. Rio de Janeiro: Lumen Juris, 2010. 